\title{
Dietary intake, intestinal infection, and safe drinking water among children with anemia in Peru: a cross-sectional analysis
}

\author{
Christopher M. Westgard ${ }^{1,2^{*}}$ (D), Luis A. Orrego-Ferreyros ${ }^{1,3}$, Liz Franco Calderón ${ }^{1}$ and Alexandra M. Rogers ${ }^{4}$
}

\begin{abstract}
Background: Anemia is a major public health concern that is present in $41.7 \%$ of children under 5 worldwide. The prevalence of anemia in Peru was $43.6 \%$ in 2017, a decrease by only $6.8 \%$ in 8 years. Despite great efforts made by the government to reduce anemia by distributing free multi-micronutrient supplements and promote the consumption of iron rich foods, progress has been slow. The current study sought to better understand why the prevalence remains high by analyzing the dietary intake, incidence of intestinal infectious disease, and access to safe drinking water by children with anemia in Peru.

Methods: A cross-sectional analysis was conducted using data from two national surveys that were combined by child ID. Descriptive statistics was analyzed to understand the experience of children with anemia in comparison to child without anemia. Logistic multivariate regression analyses were conducted to test the associations between anemia and dietary intake, intestinal infection, and access to safe drinking water.

Results: The sample included 586 children between 6 and 35 months. The prevalence of anemia in this population was $53 \%$. The portion of children that consumed sufficient iron to meet the recommendation for their age was $62 \%$. Of the children with anemia, $52 \%$ consumed sufficient iron to meet their recommendation, vs. $72 \%$ of children without anemia $(p<0.001)$. The children with anemia were more likely to have an intestinal infection during the previous year ( $35 \%$ vs. $26 \%, p=0.057$ ) and less likely to have access to safe drinking water $(77 \%$ vs. $86 \%, p=0.002$ ) than those without anemia. The logistic analysis revealed that having an intestinal infection increased the odds of having anemia (OR $=1.64, \mathrm{Cl} 95 \%$ [1.041-2.584]), and having access to safe drinking waters decreased the odds of having anemia (OR=0.578, [0.334-0.998]).

(Continued on next page)
\end{abstract}

\footnotetext{
* Correspondence: cmwestgard@gmail.com

'Department of Research and Innovation, Elementos, Lima, Peru

${ }^{2}$ Department of Maternal and Child Health, Gillings School of Global Public

Health, University of North Carolina at Chapel Hill, Chapel Hill, NC, USA

Full list of author information is available at the end of the article
} 
(Continued from previous page)

Conclusions: More than half of the children with anemia in Peru already consume sufficient iron to meet their daily requirement. However, they continue to have anemia, likely due to intestinal infection, such as diarrhea and parasites, from a lack of access to safe drinking water and hygienic practices.

Keywords: Anemia, Nutrition, Diet, Iron, Intestinal infectious disease, Parasites, Water, Peru

\section{Background}

Proper nutrition in children, especially during the first 1000 days, is critical for healthy growth and development [1-4]. However, in 2016, 41.7\% of children under 5 globally suffered from anemia, commonly caused by micronutrient deficiencies [5]. The consequence of anemia on the health and economic development of communities are significant [6] Anemia can create significant developmental delays in children, weaken their immune system, and decrease the amount of energy they have available to grow and learn [7-9] A deeper understanding of anemia's etiology in diverse contexts is needed to appropriately combat the disease and reduce its effects on children's health and development.

Anemia is a multicausal problem created by micronutrient deficiencies, intestinal infections from parasites and bacteria, malaria, and genetic hemoglobin disorders [6]. Iron deficiency is the most common cause of anemia which accounts for almost half of all cases in children under 5 years of age worldwide [6]. Iron is an essential nutrient for hemoglobin and the production of red blood cells. Iron deficiency occurs when iron absorption into the blood does not meet the body's iron requirements, due to poor diet or impaired absorption, decreasing the amount of hemoglobin in the blood below the threshold of healthy levels determined by age, sex, and other factors $[7,10]$. The body's need for iron is especially high during infancy and childhood, when the body experiences rapid growth.

The risk of iron deficiency anemia globally has been linked to various socioeconomic determinants, such as poor access to proper sanitation, unhygienic practices in the household, parents' education level, family income, and family size [11-13]. Research in Peru has shown that childhood anemia is associated with poor intake of iron-rich foods, high prevalence of infectious diseases, a lack of safe water, low birth weight, and insufficient breastfeeding [14].

In Peru, $43.6 \%$ of children below 3 years old had anemia in 2017, a 6.8\% reduction since 2009 [15]. Reducing childhood anemia has become a high priority of the Peruvian National Government. The Government has created a multisectoral plan that aims to reduce anemia in children under 3 by over $24 \%$ [16]. National programs have focused primarily on providing micronutrient supplements and educational campaigns to increase children's intake of iron rich foods [17]. However, due to the multicausal nature of the disease, a multisectoral approach that goes beyond micronutrient supplementation and promoting dietary changes is needed.

The slow rate of decline of anemia in Peru in the face of extensive government efforts to reduce the prevalence merits a deeper look at the children with anemia to better understand their experience. The current prevention campaigns seem to suggest that increased consumption of iron will solve the problem of childhood anemia. The current study investigates this proposition by describing the dietary intake of children with anemia and analyzing the primary drivers of anemia independent of dietary intake. The study provides a greater understanding of the nutritional, health, and behavioral characteristics of children with anemia in Peru, to illuminate their needs and opportunities to create significant reduction in anemia.

\section{Methods}

A cross-sectional analysis was conducted with data from two public databases combined by child ID. One of the databases included information from the national survey, The Food and Nutrition Surveillance Survey for Stages of Life (FNSS), 2015 (In Spanish: Encuesta de Vigilancia Alimentaria y Nutricional por Etapas de Vida, VIANEV) [18]. The other database included administrative data from public health centers, called theHealth Benefits Report from the Integrated Health Services Systems of Comprehensive Health Insurance (ISHS), Ministry of Health 2015 (In Spanish: Reporte de Prestaciones de Salud del Sistema Integrado de Aseguramiento en Salud del Seguro Integral de Salud del Ministerio de Salud, SIAS IS) [19]. The data extracted from the ISHS corresponded with the timeframe of the FNSS (2015) to ensure the indicators from both datasets were recorded during the same timeframe.

\section{The food and nutrition surveillance survey for stages of life (FNSS)}

The FNSS is a nationally representative survey conducted by the National Center for Food and Nutrition, of the National Institute of Health (in Spanish: Centro Nacional de Alimentación y Nutrición). The survey utilized a cluster sampling survey design with randomized selection to represent the national population. The 
survey examined nutritional outcomes and dietary intake in children under 3 years.

Dietary intake was measured with a 24-h dietary recall on two non-consecutive days. The weight of each food consumed was estimated by weighting an approximately equivalent portion of the food with the survey participant. The dietary information was converted into the amount of nutrients consumed by the child during each day. To estimate the distribution of intake of nutrients, the survey used the software, PC-SIDE, developed by Iowa State University [20]. The intake of nutrients was compared to the dietary recommendations to meet estimated energy requirements (EER) by age and sex, defined by the Department of Nutrition for Health and Development of the World Health Organization [2124]. The calculation determined if each participant met the nutrient requirements for their age of each nutrient category. The complete methodology is described in the survey's final report [18].

The FNSS survey used a portable spectrophotometer to estimate hemoglobin concentration of the participants. The hemoglobin concentrations were used to diagnosis anemia using cut-off points defined by the World Health Organization. For children aged 6-59 months, the survey used the cut-off point defined by the World Health Organization of less than $11 \mathrm{~g}$ per liter [25]. Due to the method of measurement, it is not possible to distinguish between the type or cause of anemia. Iron-deficiency anemia is the most common in the population [26].

The FNSS provided information regarding the water source of households surveyed. The water source was defined as safe drinking water if it same from public water source such as public water piped into the household, shared water pipe outside of the home, or a community well [18]. The information is represented in the current study by the categorical variable, access to safe drinking water, in which $0=$ no access to a safe drinking water source and $1=$ the household has access to a safe drinking water source.

The FNSS provided information that is used by the current study to control for the effect of poverty of the household. The variable is not a key predictor of interest, but it is included in the logistic regression analysis to control for its influence. The variable, basic needs met, indicators if the home meets the basic needs of the family. The home does not meet the basic needs if it is constructed with non-structurally sound material (plastic, carboard, etc.), dirt floor, overcrowded, no toilet (indoor or outdoor), a child aged 6-12 does not attend school, or if the head of the household did not complete primary school.

The FNSS survey database provided the following variables; child met iron recommendations, child met micronutrient recommendations (iron, zinc, vitamin A), child met micronutrient and energy requirements (iron, zinc, vitamin A, and calories), anemia diagnosis, access to safe drinking water, basic needs met, sex, age, and area of residence (metropolitan Lima, urban or rural).

\section{The integrated health Services Systems of Comprehensive Health Insurance (ISHS)}

The ISHS is a public database that contains administrative data reported by all public medical centers that accepts the public health insurance [19]. It provides information on the medical care provided to the population The database is available by request from the Ministry of Health of Peru. The illnesses reported in the databased, that were diagnosed and treated in the health centers, were categorized according to the International Classification of Diseases: Preparation of Short Lists for Data Tabulation [27]. The information of interest for this study from the ISHS database is the cases of intestinal infection or parasitic disease in child in 2016. The information is represented as a binary variable that indicates if the child was diagnosed with an intestinal infectious disease $(1=$ at least 1 reported infection) or if the child has had no diagnosis of an intestinal infectious disease at a public health center during the year 2015-2016 $(0=$ no reported infection). The category of "intestinal infectious disease' for this study includes bacterial intestinal infections, viral intestinal infections, and parasitic intestinal infections.

The FNSS and ISHS survey databases were combined by the Department of Information Technology of the Integrated Health Insurance Program, upon request by the authors. The public institution combined the FNSS and ISHS survey databases with the participants' national ID number. The institution maintains confidentiality of the information and does not share any identifiable information of the participants.

\section{Analysis}

Descriptive statistics were analyzed to better understand the experience of children with anemia in comparison to child without anemia. The differences between the two groups were compared with a Chi-square test to identify if the differences were statistically significant. Two logistic analyses were conducted to assess the strength of association between the key predictors and anemia in children in Peru. The first model assessed the association between anemia and intestinal infections, intake of iron, a poverty measure, and sex. The second model assessed the association between anemia and access to safe drinking water, intake of iron, a poverty measure, and sex. The model with intestinal intake and model with access to safe drinking water are analyzed separately because intestinal infection is a mediator between 
safe drinking water and anemia, and thus blocks the flow of association through the causal path [28].

Any cases that had omitted variables were not included in the analysis. The analysis adjusted for sampling design and clustering. The analysis was conducted with STATA/SE 16.1 [29].

\section{Results}

The FNSS included 586 participants between 6 to 35 months with no omitted variables of interest of the current study. The sample was 53\% male with an average age of 20 months. The portion living in Metropolitan Lima was $35,27 \%$ in Urban areas, and 38\% in Rural areas. The basic needs of the household were not met in $36 \%$ of the families (defined by measure of poverty in Peru) [30]. The population had a 53\% prevalence of childhood anemia, with the highest prevalence found in rural areas (Rural: 64\%, Urban: 55\%, Metropolitan Lima: $40 \%)$. The portion of respondents that had access to a safe water source was $82 \%$. These findings, and the portion of children that met their recommendation for iron intake, micronutrient intake, and micronutrient and energy intake is displayed in Table 1.

The ISHS survey included 388 children aged 6-36 months that were also included in the FNSS survey. The prevalence of children who had an intestinal infectious disease in the last year was $31 \%$. The comparison between children with anemia and those without anemia revealed significant differences in nutrient intake, incidence of intestinal infection, and access to safe drinking water. Among the children with anemia, 52\% consume the recommended amount of iron for their age, while of those without anemia $72 \%$ consume the recommended amount of iron. The comparison can be seen in Table 2 .

The analysis also revealed that of the children who did not have access to safe drinking water, $47.4 \%$ had an intestinal infection, while $27 \%$ of those with safe drinking water had an intestinal disease. To treat water in the household, $85.8 \%$ (332) of the participants who do not have access to safe drinking water report boiling their water to treat it, $3.9 \%$ (15) report treating the water with chlorine, and $0.8 \%$ (3) report treating another way.

The first logistic multivariant regression analysis revealed that having an intestinal infection increases the odds of having anemia $(\mathrm{OR}=1.64$, CI 95\% [1.041-2.58], $p=0.033)$. The second logistic multivariant regression analysis revealed that having access to clean drinking water decreases the odds of anemia (OR $=0.578$, CI 95\% [0.334-0.998], $p=0.049$ ). The results of the logistic regressions are displayed in Table 3.

\section{Discussion}

The results display that $52.3 \%$ of children with anemia in Peru already consume the recommended amount of
Table 1 Characteristics of study population

\begin{tabular}{|c|c|}
\hline & $\mathrm{N}(\%)$ \\
\hline \multicolumn{2}{|c|}{ Characteristics of Study Population } \\
\hline \multicolumn{2}{|l|}{$\operatorname{Sex}^{\mathrm{b}}$} \\
\hline Male & $299(52.6)$ \\
\hline Female & $269(47.4)$ \\
\hline Age (months) ${ }^{\mathrm{b}}$ & $20 \pm 8.5^{\mathrm{a}}$ \\
\hline \multicolumn{2}{|l|}{ Area of residence ${ }^{b}$} \\
\hline Metropolitan Lima & $201(35.4)$ \\
\hline Urban & $154(27.1)$ \\
\hline Rural & $213(37.5)$ \\
\hline \multicolumn{2}{|l|}{ Basic needs met ${ }^{\mathrm{b}}$} \\
\hline No & $211(36.1)$ \\
\hline Yes & $375(63.9)$ \\
\hline \multicolumn{2}{|l|}{ Childhood Anemia ${ }^{b}$} \\
\hline No & $274(46.8)$ \\
\hline Yes & $312(53.2)$ \\
\hline \multicolumn{2}{|l|}{ Dietary uptake } \\
\hline \multicolumn{2}{|c|}{ Children that meet recommendation for iron ${ }^{b}$} \\
\hline No & $218(38.4)$ \\
\hline Yes & $350(61.6)$ \\
\hline \multicolumn{2}{|c|}{ Children that meet recommendation for iron, zinc and vitamin $A^{b}$} \\
\hline No & $282(48.1)$ \\
\hline Yes & $304(51.9)$ \\
\hline \multicolumn{2}{|c|}{$\begin{array}{l}\text { Children that meet recommendation for iron, zinc, vitamin A, protein } \\
\text { and, energy }{ }^{b}\end{array}$} \\
\hline No & $342(58.4)$ \\
\hline Yes & $244(41.6)$ \\
\hline \multicolumn{2}{|c|}{ Access to safe drinking water ${ }^{b}$} \\
\hline No & $106(18.1)$ \\
\hline Yes & $480(81.9)$ \\
\hline
\end{tabular}

${ }^{\mathrm{a} M e a n} \pm$ standard deviation

${ }^{\mathrm{b}}$ Reported from FNSS

iron in their diet. Similar results were found in a study in Peru in 2014, which showed that $51 \%$ of children under 3 met their iron uptake requirements and 60\% met their energy intake requirements [31]. In the study, they did not assess how the diet related to the prevalence of anemia. It could have been assumed that the children with anemia were those that did not consume the recommended levels of micronutrients, and so promotion of multi-micronutrient supplements and increased consumption of iron rich foods could solve the problem of anemia.

The causes of anemia include poor nutrient intake, infectious diseases, parasites, inflammation, and hemoglobinopathies [6]. The risk of anemia is greater when a population has frequent infection and does not have safe drinking water or practice good hygiene, and does not 
Table 2 Group comparison between those with anemia and those without anemia

\begin{tabular}{|c|c|c|c|}
\hline \multirow[t]{3}{*}{ Characteristic } & \multicolumn{2}{|c|}{ Children with anemia } & \multirow[t]{3}{*}{$p$-value } \\
\hline & No & Yes & \\
\hline & n (\%) & n (\%) & \\
\hline Area of residence & & & $<0.001$ \\
\hline Metropolitan Lima & $120(59.7)$ & $81(40.3)$ & \\
\hline Urban & $70(45.5)$ & $84(54.5)$ & \\
\hline Rural & $76(35.7)$ & $137(64.3)$ & \\
\hline Children that meet recommendation for iron & & & $<0.001$ \\
\hline No & $74(27.8)$ & $144(47.7)$ & \\
\hline Yes & $192(72.2)$ & $158(52.3)$ & \\
\hline Children that meet recommendation for iron, zinc, and vitamin A & & & $<0.001$ \\
\hline No & $107(39.1)$ & $175(56.1)$ & \\
\hline Yes & $167(60.9)$ & $137(43.9)$ & \\
\hline Children that meet recommendation for iron, zinc, vitamin A, protein and energy & & & 0.001 \\
\hline No & $140(51.1)$ & $202(64.7)$ & \\
\hline Yes & $134(48.9)$ & $110(35.3)$ & \\
\hline Children with an intestinal infectious disease & & & 0.057 \\
\hline None & $121(73.8)$ & $143(64.7)$ & \\
\hline At least 1 & $43(26.2)$ & $78(35.3)$ & \\
\hline Access to safe drinking water & & & 0.002 \\
\hline No & $39(14.1)$ & $73(23.4)$ & \\
\hline Yes & $235(85.9)$ & 239 (76.6) & \\
\hline
\end{tabular}

have access to education and economic opportunities [19]. We see in the current study that nearly half of the children with anemia consume the recommended amount of nutrients, but it is not being appropriately absorbed and converted into hemoglobin. We must look beyond diet to significantly reduce the drivers of anemia. By integrating medical care data with the national nutrition survey, we were able to investigate other drivers of anemia beyond nutrition uptake. Intestinal infectious diseases, including diarrhea and helminth infections, have been linked to the development of anemia [32-36]. The logistic regression displayed that the presence of an intestinal infection increases the odds of having anemia $(\mathrm{OR}=1.64, p=0.033)$, with meeting iron requirements included in the model $(\mathrm{OR}=0.51, p=0.002)$. The results help explain why so many children have anemia, following years of national campaigns to provide micronutrient supplements and education campaigns to increase iron

Table 3 Logistic Regression Analysis on anemia

\begin{tabular}{|c|c|c|c|c|}
\hline$N=398$ & Odds Ratio & Standard Error & $P$-value & 95\% Confidence Interval \\
\hline \multicolumn{5}{|l|}{ Analysis 1: } \\
\hline Iron Requirements & 0.505 & 0.109 & 0.002 & $0.331-0.770$ \\
\hline Intestinal Infectious Disease & 1.640 & 0.380 & 0.033 & $1.041-2.584$ \\
\hline Male & 1.182 & 0.250 & 0.428 & $0.782-1.789$ \\
\hline Poverty & 1.473 & 0.323 & 0.077 & $0.959-2.262$ \\
\hline Intercept & 1.378 & 0.310 & 0.155 & $0.886-2.143$ \\
\hline \multicolumn{5}{|l|}{ Analysis 2: } \\
\hline Iron Requirements & 0.539 & 0.116 & 0.004 & $0.353-0.822$ \\
\hline Safe Drinking Water & 0.578 & 0.161 & 0.049 & $0.334-0.998$ \\
\hline Male & 1.195 & 0.252 & 0.399 & $0.789-1.801$ \\
\hline Poverty & 1.364 & 0.298 & 0.155 & $0.889-2.093$ \\
\hline Intercept & 2.469 & 0.771 & 0.004 & $1.339-4.551$ \\
\hline
\end{tabular}


uptake. Strategies that do not address the presence of disease in children will continue to produce limited effects on the reduction of anemia [24-26]. We must look at ways to prevent diarrhea, infectious diseases, and helminth infections in order to reduce children's risk of anemia.

Access to safe drinking water is associated with a lower risk of diarrhea and helminth infections; and diarrhea and helminth infections can cause anemia [32, 33, 37]. The current study found that children with access to safe drinking water are less likely to have anemia $(\mathrm{OR}=0.58, p=0.049)$. However, in a country that is prioritizing the reduction of anemia, it is worrisome that $29 \%$ of the rural population still do not have access to safe drinking water (2019) [15]. This study highlights the importance of improving access to safe drinking water and promoting proper sanitation and hygiene to reduce children's risk for anemia.

The study has limitations created by the nature of the data included in the analysis. Because the data are crosssectional, we cannot establish causality nor rule out the possibility of reverse causality. The children could have experienced a change in their diet following a diagnosis of anemia by the health center or self-diagnosis by their caregivers. However, given that anemia evaluations are infrequent in Peru and extremely difficult to diagnosis by observing the condition of the child, it is unlikely the diet at the time of the survey was influenced by a previous diagnosis of anemia. Additionally, the fact remains that if the children were living in sanitary conditions the change in diet should have pulled them out of anemia (assuming the diet had been maintained for weeks prior to the survey). Another limitation of the data is the measurement of intestinal infectious disease because it includes only the cases that are reported in the health center, and thus misses many incidences of diseases that are not reported due to poor access to health services and poor reporting in the health center [38]. The number of children that had experienced an intestinal infectious diseases is expected to be much higher. Nutritional surveys that utilize self-reporting also have their limitations that must be considered, included over or under reporting the amount of food consumed during the previous day. However, the FNSS attempted to reduce the bias by surveying each home on two separate, non-consecutive days. Finally, the FNSS did not include information on breastfeeding, which is a significant limitation when calculating the intake of nutrients by children less than 2 years of age.

\section{Conclusion}

The present study has provided us with the opportunity to explore more deeply the dietary and disease profile of children with anemia in Peru. The results give us a better understanding of the factors that are helping to maintain a high prevalence of anemia in children below 3 years of age. The analysis hopes to show that the causes of anemia are diverse, and thus demand a diverse national strategy. The problem cannot be solved while children continue to live with poor sanitation and high incidence of disease. The promotion of iron consumption and micronutrient supplements alone will not be enough.

Our study has found that access to safe drinking water and incidence of intestinal infection are significantly associated with anemia. To reduce the incidence of intestinal infections and anemia, national policies to improve access to safe drinking water and sanitation must be implemented. It is essential that any approach to combat anemia in Peru focuses not only on the dietary causes of anemia, but also addresses the social determinants that affect children's health.

\section{Abbreviations \\ FNSS: Food and Nutrition Surveillance Survey for Stages of Life; ISHS: Health Benefits Report from the Integrated Health Services Systems of Comprehensive Health Insurance; SIASIS: Reporte de Prestaciones de Salud del Sistema Integrado de Aseguramiento en Salud del Seguro Integral de Salud del Ministerio de Salud; VIANEV: Encuesta de Vigilancia Alimentaria y Nutricional por Etapas de Vida}

\section{Acknowledgements}

Not applicable.

\section{Authors' contributions}

CMW, LAOF, and LFC designed the study, analyzed the data, and wrote the manuscript. AMR helped write the manuscript and revised the analysis. All authors have read and approved the manuscript.

\section{Funding}

The authors were partially supported to conduct the research by Elementos. The authors also volunteered their time to conduct the study.

\section{Availability of data and materials}

The deidentified dataset supporting the conclusions of this article is available in the figshare repository, https://doi.org/10.6084/m9.figshare.12574001. Public access to the database is open.

\section{Declarations}

Ethics approval and consent to participate

The current study was submitted to and approved by the Institutional Review Board of the Office of Human Research Ethics of the University of North Carolina - Chapel Hill (Reference ID 281768). The Institutional Review Board determined that the research activity does not require IRB Approval (Study \# 20-1029). Following this determination and and confirmation with the local Peruvian Institutional Review Board, San Bartolome, the study was not submitted for approval by a Peruvian IRB.

\section{Consent for publication}

Not applicable.

\section{Competing interests}

The authors declare that they have no competing interests.

\section{Author details}

'Department of Research and Innovation, Elementos, Lima, Peru.

${ }^{2}$ Department of Maternal and Child Health, Gillings School of Global Public Health, University of North Carolina at Chapel Hill, Chapel Hill, NC, USA.

${ }^{3}$ Faculty of Public Health and Administration, Universidad Peruana Cayetano 
Heredia, Lima, Peru. ${ }^{\text {DD }}$ epartment of International Health, Bloomberg Schoo of Public Health, Johns Hopkins University, Baltimore, MD, USA.

\section{Received: 3 July 2020 Accepted: 4 March 2021}

\section{Published online: 03 June 2021}

\section{References}

1. Black MM, Walker SP, Fernald LCH, et al. Early childhood development coming of age: science through the life course. Lancet. 2017;389(10064):7790. https://doi.org/10.1016/S0140-6736(16)31389-7.

2. Grantham-McGregor S, Cheung YB, Cueto $S$, et al. Developmental potential in the first 5 years for children in developing countries. Lancet. 2007; 369(9555):60. https://doi.org/10.1016/S0140-6736(07)60032-4.

3. Engle PL, Fernald LC, Alderman $H$, et al. Strategies for reducing inequalities and improving developmental outcomes for young children in low-income and middle-income countries. Lancet. 2011;378(9799):1339-53. https://doi. org/10.1016/S0140-6736(11)60889-1

4. Walker SP, Wachs TD, Grantham-McGregor S, et al. Inequality in early childhood: risk and protective factors for early child development. Lancet. 2011;378(9799):1325-38. https://doi.org/10.1016/S0140-6736(11)60555-2.

5. Prevalence of Anemia among Children (\% of Children under 5) | Data. The World Bank; 2016. Accessed September 27, 2019. https://data.worldbank. org/indicator/SH.ANM.CHLD.ZS

6. World Health Organization; Nutritional Anaemias: Tools for effective prevention and control. 2017.

7. Desforges JF, Oski FA. Iron deficiency in infancy and childhood. New England J Med. 1993;329(3):190-3.

8. Carter RC, Jacobson JL, Burden MJ, et al. Iron deficiency anemia and cognitive function in infancy. Pediatrics. 2010;126(2):e427-34. https://doi. org/10.1542/peds.2009-2097.

9. Westgard C, Alnasser Y. Developmental delay in the Amazon: the social determinants and prevalence among rural communities in Peru. PLoS One. 2017:12(10):e0186263. https://doi.org/10.1371/journal.pone.0186263.

10. Camaschella C. Iron-deficiency Anemia. N Engl J Med. 2015;372(19):1832-43. https://doi.org/10.1056/NEJMra1401038.

11. Osório MM. Determinant factors of anemia in children. J Pediatr. 2002;78(4): 269-78. https://doi.org/10.2223/jped.860.

12. Subramaniam G, Girish M. Iron deficiency anemia in children. Indian J Pediatr. 2015;82(6):558-64. https://doi.org/10.1007/s12098-014-1643-9.

13. Solar O, Irwin A. A Conceptual Framework for Action on the Social Determinants of Health. Social Determinants of Health Discussion Paper 2: World Health Organization; 2010.

14. Sobrino M, Gutierrez Villafuerte C, Ledo Alves Da Cunha AJ, Alarcon J. Desnutrición infantil en menores de cinco años en Perú: Tendencias y Factores Determinantes. Rev Panam Salud Publica. 2014;35(2):104-12.

15. Encuesta Demográfica y de Salud Familiar 2019 - Nacional y Regional. Instituto Nacional de Estadística e Informática, Peru; 2019. https://proyectos. inei.gob.pe/endes/2019/ppr/Indicadores_de_Resultados_de_los_Programas_ Presupuestales_ENDES_Primer_Semestre_2019.pdf

16. Ministerio de Desarrollo e Inclusion Social, Peru. Plan Multisectorial de Lucha Contra La Anemia. 2018.

17. Anemia En La Población Infantil Del Perú: Aspectos Clave Para Su Afronte. Instituto Nacional de Salud, Peru; 2017. http://www.ins.gob.pe/repositorioa ps/0/4/jer/evidencias/ANEMIAFINAL_v.03mayo2015.pdf.

18. Informe Final. Encuesta: Vigilancia Alimentaria y Nutricional Por Etapas de Vida - VIANEV - Niños Menores de 36 Meses - 2015. Ministerio de Salud, Instituto National de Salud, Centro Nacional de Alimentacion y Nutricion; 2016. https://web.ins.gob.pe/sites/default/files/Archivos/cenan/van/vigilacia_ poblacion/Informe VIANEV Ninos_2015.pdf

19. Ministerio de Salud de Peru; Seguro Integral de Salud. Base de Datos de Prestaciones de Salud. 2015-2016. 2017.

20. Software for Intake Distribution Estimation - lowa State University. Accessed October 4, 2020. http://www.side.stat.iastate.edu/

21. Fats and Fatty Acids in Human Nutrition -Report of an Expert Consultation. Food and Agriculture Organization of the United Nations.; 2010. http:// www.fao.org/3/a-i1953e.pdf

22. Protein and Amino Acid Requirements in Human Nutrition. Report of a Join FAO/WHO/UNU Expert Consultation. World Health Organization; 2007. http:// www.who.int/nutrition/publications/nutrientrequirements/WHO_TRS_935/en/

23. Human Energy Requirements. Report of Joint FAO/WHO/UNU Expert Consultation.; 2001. http://www.fao.org/3/a-y5686e.pdf
24. Vitamin and Mineral Requirements in Human Nutrition : Report of a Joint FAO/WHO Expert Consultation. Joint FAO/WHO Expert Consultation on Human Vitamin and Mineral Requirements; 1998.

25. Prevention and Control of Iron-Deficiency Anaemia in Women and Children. Report of the UNICEF/WHO Regional Consultation. WHO Regional Office for Europe, UNICEF Regional Office for Central and Eastern Europe the Commonwealth of Independence States and the Baltic States; 2001. Accessed October 4, 2020. https://www.who.int/nutrition/publications/ micronutrients/anaemia_iron_deficiency/e73102/en/

26. World Health Organization; Iron Deficiency Anaemia Assessment, Prevention, and control a guide for Programme manager. 2001. https://www.who.int/ nutrition/publications/en/ida_assessment_prevention_control.pdf

27. Becker R. International Classification of Diseases: Preparation of Short Lists for Data Tabulation. Epidemiol Bull. 2002;23:4 Accessed April 4, 2020. https:// www.paho.org/english/dd/ais/be_v23n4-short list.htm.

28. Hernan M, Robins J. Causal inference: what if. Boca Raon: Chapman \& Hall/CRC; 2020.

29. Stata: Software for Statistics and Data Science. Accessed October 2, 2018. https://www.stata.com/

30. Metodología Para La Medición de La Pobreza En El Perú. Instituto Nacional de Estadistica E Informatica, Peru; 2000. https://www.inei.gob.pe/media/ MenuRecursivo/metodologias/pobreza01.pdf

31. Tarqui Mamani CB, Rosales Pimentel S. informe Technico: Vigilancia de Indicadores Nutricionales. Consumo de Alimentos En Niños Peruanos de 6 a 35 Meses 2013-2014. Ministerio de Salud, Instituto Nacional de Salud, Centro Nacional de Alimentacion y Nutricion; 2015. https://web.ins.gob.pe/ sites/default/files/Archivos/cenan/van/vigilacia_poblacion/CONSUMO\%2 ODE\%20ALIMENTOS\%20EN\%20NINOS\%20PERUANOS\%20DE\%206\%20A\%203 5\%20MESES\%202013-2014.pdf

32. Larsen DA, Grisham T, Slawsky E, Narine L. An individual-level meta-analysis assessing the impact of community-level sanitation access on child stunting anemia, and diarrhea: Evidence from DHS and MICS surveys. PLoS Negl Trop Dis. 2017;11(6):e0005591. https://doi.org/10.1371/journal.pntd.0005591.

33. Wolf J, Prüss-Ustün A, Cumming $O$, et al. Systematic review: assessing the impact of drinking water and sanitation on diarrhoeal disease in low- and middle-income settings: systematic review and meta-regression. Tropical Med Int Health. 2014;19(8):928-42. https://doi.org/10.1111/tmi.12331.

34. Bechir M, Schelling E, Hamit MA, Tanner M, Zinsstag J. Parasitic infections, anemia and malnutrition among rural settled and mobile pastoralist mothers and their children in Chad. Ecohealth. 2012;9(2):122-31. https://doi. org/10.1007/s10393-011-0727-5.

35. Jonker FAM, Calis JCJ, Phiri K, et al. Real-time PCR demonstrates Ancylostoma duodenale is a key factor in the etiology of severe anemia and iron deficiency in Malawian pre-school children. PLoS Negl Trop Dis. 2012;6(3):e1555. https://doi.org/10.1371/journal.pntd.0001555.

36. Evaluación Basal de Anemia Por Deficiencia de Hierro y Folatos En Mujeres En Edad Fértil y En Niños y Niñas de 24 a 59 Meses En Lima Metropolitana. Instituto Nacional de Salud; 2006. Accessed August 21, 2019. http://catalog. ihsn.org/index.php/citations/82226

37. Humphrey JH, Mbuya MNN, Ntozini R, et al. Independent and combined effects of improved water, sanitation, and hygiene, and improved complementary feeding, on child stunting and anaemia in rural Zimbabwe: a cluster-randomised trial. Lancet Glob Health. 2019;7(1):e132-47. https:// doi.org/10.1016/S2214-109X(18)30374-7.

38. Westgard CM, Rogers A, Bello G, Rivadeneyra N. Health service utilization, perspectives, and health-seeking behavior for maternal and child health services in the Amazon of Peru, a mixed-methods study. Int J Equity Health. 2019:18(1):155. https://doi.org/10.1186/s12939-019-1056-5.

\section{Publisher's Note}

Springer Nature remains neutral with regard to jurisdictional claims in published maps and institutional affiliations. 